\title{
Open Communication, Career Development Practices and Organizational Citizenship Behaviour in Kenya Forest Service
}

\author{
Judith Chepkemoi*, Mwangi Kungu, Razia Mbaraka \\ Department of Management Science and Entrepreneurship, Moi University, School of Business \& Economics, Eldoret, Kenya
}

Email address:

Jchepkemoi26@gmail.com (J. Chepkemoi)

${ }^{*}$ Corresponding author

\section{To cite this article:}

Judith Chepkemoi, Mwangi Kungu, Razia Mbaraka. Open Communication, Career Development Practices and Organizational Citizenship Behaviour in Kenya Forest Service. Journal of Human Resource Management. Vol. 8, No. 3, 2020, pp. 172-180.

doi: $10.11648 /$ j.jhrm.20200803.18

Received: June 6, 2020; Accepted: June 28, 2020; Published: July 17, 2020

\begin{abstract}
The study determined the moderating role of career development practices on the relationship between open communication and organizational citizenship behaviour. The study was anchored on the social exchange theory. The study employed explanatory research design ingrained with the pragmatism philosophy. The target population of the study comprised of 702 employees drawn from Kenya Forest Service North Rift Conservancy. Multi stage sampling technique was used to select a sample size of 248 respondents. The primary data for the study was collected using closed ended questionnaires and semi-structured interview schedule. Data was analyzed quantitatively using descriptive statistics (frequencies, percentages, means, standard deviation) and inferential statistics (Regression, Correlation and ANOVA) while qualitative data was analyzed using thematic analysis. The hypothesis was tested using multiple regression model and hierarchical regression for moderation. Findings of hierarchical regression showed that career development practices moderate the relationship between open communication and OCB $\left(\beta=.24, \mathrm{p}<0.05, \mathrm{R}^{2} \Delta=.01\right)$. This implies that firms with career development practices have higher probability of improving OCB with open communication. It therefore calls for formulation and promotion of open communication and its effective implementation. Moreover, in order for open communication to enhance OCB, organization needs to implement career development practices.
\end{abstract}

Keywords: Career Development Practices, Open Communication, Organizational Citizenship Behavior

\section{Introduction}

Globally, organizations increase their employees' citizenship behaviour to enhance retention. In this regard, OCB remains an international phenomenon considered as one of the biggest obstacles for organizations in achieving their strategic plans and gaining competitive advantages [1]. This gives credence to the adoption of retention strategies such as open communication strategies owing to their dyadic relationship with OCB. [2] underscores that there is a positive linkage between OCB and Employee Retention practices in organizations. This justifies the use of retention strategies to make employees rise beyond their given responsibilities and authorities thus OCB. This is because organizational success can only be achieved when employees perform more than mere completion of the required job task [3]. Previous research shows that if the employee turnover increases then the organization effectiveness is decreased. There is an inverse relation between employee turnover and organizational performance. Subsequently a myriad of recommendations encourage employees to improve on OCB because it is crucial in making decisions to either quit or be retained in an organization. More importantly, the linkage between OCB and employees retention remains vital.

An understanding of the relationship between OCB and employees retention has received considerable attention over the last decades [2]. The employees who stay for a longer duration are familiar with the company policies, guidelines as well as rules and regulations and thus can contribute more effectively than individuals who come and go [4]. Therefore there is evidence to 
affirm that employee retention may influence the organizational citizenship behaviour. This is corroborated by [5] who indicated that there is a positive relationship between employee retention and OCB, while [6] suggested that more retention might negatively affect OCB. Nonetheless, [7] showed no effect of retention on OCB. However, the OCB as an outcome depends on the retention strategies used by an organization. These mixed findings obviate the need for further research on the relationships between OCB and employee retention. With reference to these inconsistencies in the past research on the claimed relationship, [8] cited in [9] have recommended that when the relationship between a predictor and a criterion variable is found unexpectedly weak or inconsistent a moderating variable should be introduced.

Career and development opportunities also moderated the indirect relationship between openness to experience and intention to quit through perceived sacrifice commitment [10]. Alternatively, if workers realize that the organizational development guidelines are not in line with their career aspirations i.e in making certain commitments regarding their workers, it will force them to only perform within their job description hence affecting their extra role behaviors [11]. This gives credence to the fact that the success or failure of retention strategies used is exclusively dependent upon the perception of employees regarding these strategies, which supplicates the importance of interrogating the role of contingent factors on the relationship between employee retention strategies and organizational citizenship behaviour.

However, limited studies have been conducted in the Kenyan context focusing on career development practices moderating the relationship between retention strategies and OCB. Besides, little is known on the role of career development practices on the relationships between employee retention strategies and organizational citizenship behaviour in Kenya Forest Service, North Rift Conservancy. Therefore, it was speculative how the presence or absence of career development practices affects the relationships between employee retention strategies and organizational citizenship behaviour. Based on the foregoing, this study looked at how career development practices moderates the relationships between employee retention strategies and Organizational citizenship behaviour of employees at Kenya Forest Service, North Rift Conservancy. The choice of Kenya forest was based on the fact that non-managers at Kenya Forest Service suffer low satisfaction index with the work environment at $56.5 \%$ compromising on their OCB [12]. Low satisfaction levels within work environment suggest poor retention strategies and low OCB in the service. Low remuneration, un-harmonized schemes of service, weak implementations of training policy, weak implementation of performance management system, promotion and deployment, lack of policy on gender equality and job insecurity have been linked to poor workers retention [13]. In order to achieve good service delivery the organization ought to interrogate the effect of their retention strategies on employee discretionary behavior. Thus, the main objective of this study was to explore the moderating role of career development practices on the effect of open communication on organizational citizenship behaviour in Kenya Forest Service, North Rift Conservancy

\section{Theoretical and Literature Review}

\subsection{Theoretical Review}

From the literature reviewed, the following the study was anchored social exchange theory. [14] introduced Social exchange theory and referred to "Social Behaviour" in his work as "Exchange" [15]. Social exchange was further defined as the exchange of activity, tangible or intangible, more or less rewarding or costly between at least two persons. That is, explaining the process of negotiated exchanges between parties. The theme of this theory is that social behaviour is moderated by the amount of additions or withdrawals of bargainable instruments [16]. Organizational citizenship behaviour is seen as one of the core outcomes of social exchanges in employment relationship because of its discretionary nature [17].

According to social exchange theory [18] posits that exchanges are based on initiated and voluntary actions by either employer or employee and the expectation that the other party will eventually reciprocate these actions. If one party does not meet their obligations the imbalance in exchange relationship will force the other party to either increase or withhold their efforts to restore equivalence [19]. Following this argument, employees are expected to regulate their engagement in organizational citizenship behaviour relative to what they receive, or intending to receive in future from their employer.

Employees will withhold discretionary behaviours if they feel unfairly treated or choose to engage in OCB to reciprocate good or fair treatment from the organization [20]. This implies that organizational citizenship behaviour develops as an effect of social exchanges between employees and their employers and therefore organizations. Therefore, the employer has to provide a warm environment for OCB growth to enhance employee commitment hence their retention is made possible. The practical application of this theory is that employees feel pleased to perform more than expected from them when the firms cares for them.

\subsection{Review of Literature (Hypothesis Development)}

Communication is the backbone of any company; the joint that brings together all departments of a company; the lubricant that smoothen the company's functions; the string that ties the structure together and a fastening agent that cements all organizational affairs [21]. The aforementioned statement indicates the magnitude played by communication in today's organizations. Human resources constitute the biggest challenge among other factors of production because it calls for skillful management of feelings, emotions and thoughts to enhance OCB for heightened productivity [22].

Organizational communication formulates different kinds of social structures bringing up networks and teams in order to ensure workers' satisfaction and commitment in their roles 
[23]. Through timely and relevant information dispersed, communication in the organization is mandated to ensuring familiarity of workers of what is expected from them in terms of achieving the set individual targets [24]. The exchange of information between the employees and the management is very essential during hiring and retention of workers in a company. This justifies that communication can be used as a means of ensuring OCB through building of interpersonal relationships, transparency and effective commitment [25]. Due to the significance of this variable in organizational success, much attention has been given to its study on organizational behavior research. Most scholars have also found a positive link between communication and employee performances, while low employee commitment attributed to poor communication in most organizations [26].

[27] noted that the positive effects of high-quality involved supervisor-subordinate relationships on subordinate behavioural and performance outcomes lead to more commitments by employees. [28] revealed positive association between management's direct communication to employees and the various forms of OCB. Hence, stressing this conceptualization. He noted that if employees feel themselves in high-quality open communication relationship with management, then they are likely to reciprocate the organization by engaging in $\mathrm{OCB}$

From the reviewed literature, communication cues play an important role in engendering satisfaction among employees in organizations hence OCB. However, communication in most of the related studies has been considered as a one-dimensional construct, while the present study specifically proposed frequency of communication and efficiency of channels of communication predictors of organizational citizenship behaviour. Besides majority of studies have looked at direct link between communication and OCB in non-Kenyan context that espouses the need for further interrogation on how communication affect OCB as moderated by career development in the Kenyan context. Thus, the study hypothesized that:

$\mathrm{H}_{1}$ : Open communication positively affect organizational citizenship behavior

The major role of employee retention strategies is to enable employees stick to an organization. Empirical studies have shown positive linkage between employee retention practices and OCB in the effort of organizations to retain staff in the past instances [2]. Therefore there is evidence to affirm that employee retention strategies may affect organizational citizenship behavior. This is corroborated by [5] who indicated that there is a positive relationship between employee retention strategies and OCB. This implies that the organization should critically look at its retention strategies and interrogate their compatibility with the needs of the employees if it is to maximize on their OCB. However authors have faulted the relationship between the HRM practices and its outcomes [29]. This indicates that the introduction of mediator or a moderator in the relationship between HRM practices and its outcomes is of necessity [30].

In an unpredictable and uncertain environment with expanding requirement for skilled labour, organizations view career development more as a practical opportunity to recruit and keep capable workers [31]. High performers and non hourly workers were more likely to cite advancement opportunities and organizational prestige as reasons for staying, whereas low performers and hourly employees were more likely to cite extrinsic rewards [32]. Interviews with Taiwan hotel workers revealed that more than $80 \%$ of respondents had resigned from a job to pursue career advancement while $70 \%$ had experienced recruitment propositions from other hotels [33]. In this regard when employee are aware of the upcoming plan concerning their career growth, they tend to be more loyal and commitment. Therefore, career path development seems as a vital practice for attaining better employees' discretionary behaviours. Career development consists of actions undertaken by workers (career planning) and the organization (career management) to encounter career objectives and job necessities and hence is critical for realizing career planning and management [34].

[35] studied the moderating role of work locus of control in relationship between Interpersonal Communication and Organizational Citizenship Behaviour. The study focused on the variables which are due to the direct impact on the behavior of an employee and on the orientation thereof towards organizational outcomes being concentrated on interpersonal relationships. Data was collected using an online survey method of 223 employees from various organizations coming from both public and private sectors organizations from Romania. The findings of the study revealed that WLOC can moderate the relationship between IC and OCB. The results revealed that individuals with a higher I-WLOC show higher availability and skill in communication process, with positive results to OCB. The study also found out that work locus of control associated with career development moderates the relationship between Interpersonal Communication and Organizational Citizenship Behaviour

There are several retention strategies, which affects organizational citizenship behaviour in most organizations some of which are financial rewards and employee benefits, job enrichment, training and development opportunities, work environment, and work-life balance, open communication, leadership skills [36]. When there is a relation between peer support and employee retention, employee who stay in an organization are expected to have a positive impact on the organization especially on organizational citizenship behaviour. Therefore, improving organizational citizenship behaviour through proper retention strategies is vital in attracting and retaining the human resources, the key contributors in organizational success. To date little has been done on the relationship that exists between retention strategy, organizational citizenship behaviour and career development in most organizations in Kenya which calls for more studies.

$\mathrm{H}_{2}$ : At higher levels of career development practices, Open communication positively affect organizational citizenship behavior 


\section{Material and Methods}

This study adopted explanatory research design in pragmatic research philosophy which enables the researcher to simultaneously answer confirmatory questions regarding the moderating effect of succession management on the relationship between retention strategies and organizational citizenship behaviour, through use of closed ended questionnaires and semi structured interview schedules. The study adopted a sampling formula proposed by [37] from the table, the sample corresponding to a population of 702 is 248 respondents that was selected for this study. The researcher used purposive sampling to pick one administrator from each county and who was interviewed with the goal of getting detailed information concerning the relationship that exist between the variables under study. Multistage sampling technique was used to narrow down to the employees. Cluster random sampling technique was used to select the six counties in North rift conservancy. The study developed questionnaires based on the research objectives and hypotheses to collect data. The researcher employed closed ended questions with Likert type statements.

\subsection{Measurement, Reliability and Validity of Research Variables}

To measure the research variables, the study first determined the indicators/parameters of each variable and then employed Likert scale to measure independent variables, dependent variables and the moderator. The scale comprised of an interval scale of 1-5 (where; $1=$ strongly disagree, $2=$ disagree, $3=$ undecided, $4=$ agree, and $5=$ strongly agree) .

Organizational Citizenship Behaviour

OCB usually have five dimensions including altruism, courtesy, conscientiousness, sportsmanship and civic virtue.
The five dimensions were measured using a set of 24 items based on the conceptual work of [38] and developed by [7].

Open Communication

Open communication was measured using organizational communication policy, communication with managers, communication with coworkers [39].

Career Development

Career development was measured using the following items: career planning, training and development, coaching and mentoring, career counseling, talent management and succession planning [40].

Factor analysis was employed in this regard to help in identifying the actual number of factors that measured each construct as perceived by the respondents. The validity of the instrument was measured through Bartlett's Test of Sphericity [41]. The component factor analysis with varimax rotation was conducted in all variables to extract factors from each construct. According to [42] all items loading below 0.50 were deleted and those with more than 0.50 loading factor retained. The items were well loaded into their various underlying variable structure of dimensions. The factor analysis results revealed Eigen value were above the accepted value of 1 [43]. Thus, the items were appropriate to explain the variable. Moreover, from the Table 1, Bartlett's Test of Sphericity produced a significant Chi-Square $\left(\chi^{2}\right)(\rho<0.05)$ and Kaiser Meyer - Olkin measure of sampling adequacy was above the acceptable value of 0.50 (Field, 2005), showing that it was appropriate to subject data for factor analysis on this variable of Knowledge sharing behaviour [44]. In the current study, Cronbach's Alpha was used as a measure of internal consistency. The instruments were considered reliable when their reliability coefficients were above the recommended 0.7 thresholds [45].

Table 1. Measurement, Reliability and Validity.

\begin{tabular}{|c|c|c|c|c|c|}
\hline \multirow{2}{*}{$n=194$} & \multirow{2}{*}{ Mean } & \multirow{2}{*}{ loadings } & \multicolumn{3}{|l|}{ Bartlett's Test } \\
\hline & & & Approx. Chi-Square & Eigenvalues & $\%$ of $\mathrm{CV}$ \\
\hline \multicolumn{3}{|c|}{ open communication $(\mathrm{KMO}=.83$, Crobanch Alpha $=0.88)$} & $946.69 *$ & 4.72 & 42.94 \\
\hline OP1 & 4.02 & 0.88 & & & \\
\hline OP2 & 4.10 & 0.78 & & & \\
\hline OP3 & 4.06 & 0.77 & & & \\
\hline OP4 & 3.75 & 0.55 & & & \\
\hline OP5 & 4.02 & 0.78 & & & \\
\hline OP7 & 3.82 & 0.82 & & & \\
\hline \multicolumn{3}{|c|}{ OCB $(\mathrm{KMO}=.82$, Cronbach Alpha $=0.90)$} & 2610.653 & 5.116 & 42.63 \\
\hline OCB1 & 4.03 & 0.52 & & & \\
\hline OCB2 & 3.96 & 0.54 & & & \\
\hline OCB3 & 4.02 & 0.61 & & & \\
\hline OCB4 & 4.03 & 0.59 & & & \\
\hline OCB5 & 4.15 & 0.60 & & & \\
\hline OCB7 & 3.90 & 0.66 & & & \\
\hline OCB8 & 4.08 & 0.76 & & & \\
\hline OCB9 & 4.03 & 0.62 & & & \\
\hline OCB10 & 4.02 & 0.71 & & & \\
\hline OCB11 & 4.01 & 0.63 & & & \\
\hline OCB12 & 3.94 & 0.54 & & & \\
\hline OCB13 & 3.92 & 0.50 & & & \\
\hline OCB14 & 3.96 & 0.54 & & & \\
\hline OCB 15 & 3.67 & 0.68 & & & \\
\hline
\end{tabular}




\begin{tabular}{|c|c|c|c|c|c|}
\hline \multirow{2}{*}{$\mathrm{n}=194$} & \multirow{2}{*}{ Mean } & \multirow{2}{*}{ loadings } & \multicolumn{3}{|l|}{ Bartlett's Test } \\
\hline & & & Approx. Chi-Square & Eigenvalues & $\%$ of CV \\
\hline OCB16 & 4.02 & 0.58 & & & \\
\hline \multicolumn{3}{|c|}{ Career development practices $(\mathrm{KMO}=. .79$, Cronbach Alpha $=0.84)$} & $691.208 *$ & 3.91 & 45.52 \\
\hline CDP1 & 3.96 & 0.59 & & & \\
\hline CDP2 & 4.02 & 0.77 & & & \\
\hline CDP3 & 4.10 & 0.81 & & & \\
\hline CDP4 & 4.06 & 0.62 & & & \\
\hline CDP5 & 3.99 & 0.65 & & & \\
\hline CDP6 & 4.09 & 0.65 & & & \\
\hline CDP7 & 3.93 & 0.69 & & & \\
\hline CDP8 & 3.97 & 0.73 & & & \\
\hline
\end{tabular}

Extraction Method: Principal Component Analysis.

\subsection{Analytic Model}

The study used hierarchical multiple linear regression to test for moderation effects [8]. First, control variables in the model were regressed against OCB for potential direct effects. Secondly, control variables and retention strategies aspects were regressed against OCB. Thirdly, moderating variable was introduced and regressed together with other variables. Therefore, the interaction term between predictor and moderating variables was obtained by multiplying the two variables that produced an interaction effect done at different stages for each individual interaction as specified in the hierarchical regression models below:

The model specification was as follows:

$$
\begin{gathered}
\mathrm{Y}=\beta_{0}+\mathrm{C}+\varepsilon \\
\mathrm{Y}=\beta_{0}+\mathrm{C}+\beta_{1} \mathrm{X}_{1}+\varepsilon \\
\mathrm{Y}=\beta_{0}+\mathrm{C}+\beta_{1} \mathrm{X}_{1}+\beta_{5} \mathrm{M}+\varepsilon \\
\mathrm{Y}=\beta_{0}+\mathrm{C}+\beta_{1} \mathrm{X}_{1}+\beta_{2} \mathrm{M}+\beta_{3} \mathrm{X}_{1} * \mathrm{M}+\varepsilon
\end{gathered}
$$

Where:

$Y=$ Organizational Citizenship Behaviour;

$\beta_{0}=$ constant term or intercept;

$C=$ control variables in the model;

$\beta_{1} \ldots \ldots \beta_{4}=$ the coefficients of the variables in the model; $x_{1}=$ Open Communication;
$\mathrm{M}=$ Moderator (Career development practices) $\varepsilon=$ error term in the model.

\section{Findings and Discussion}

This presents the results and findings of the study according to the research objectives and hypotheses. The data was prepared for analysis by ensuring it met the minimum requirements for quantitative analysis. The questionnaires were therefore visually checked and tested for outliers, for missing values and unfilled parts as well as for normality distribution.

\subsection{Univariate Analysis}

After factor analysis all items that did not meet loading criteria were dropped and data was transformed from categorical to interval scale by getting the average score for all items in each variable. Table 1 shows the results on data transformation. From the findings, career development practices (4.02) and organizational citizenship behavior (mean $=4.02$ ). The implication is that the leadership at Kenya Forest Service is key to the career development of its employees. The standard deviations for all the variables were less than 1 indicating less variation in the responses. Finally, all independent variables and the dependent variable were normally distributed as shown in Table 2 below.

Table 2. Correlation Analysis.

\begin{tabular}{lllllllll}
\hline & Mean & Std. Deviation & $\mathbf{1}$ & $\mathbf{2}$ & $\mathbf{3}$ & $\mathbf{4}$ & $\mathbf{5}$ & $\mathbf{6}$ \\
\hline 1 & 4.02 & 0.54 & 1 & $.801^{* *}$ & 1 & & & \\
2 & 3.96 & 0.76 & $.802^{* *}$ & $.768^{* *}$ & 1 & & \\
3 & 4.02 & 0.52 & 0.061 & -0.124 & -0.05 & 1 & \\
4 & 1.47 & 0.50 & 0.055 & -0.008 & 0.027 & -0.098 & 1 & \\
5 & 2.55 & 0.77 & 0.134 & 0.068 & 0.105 & 0.037 & $.164 *$ \\
6 & 2.74 & 0.75 & -0.046 & -0.051 & -0.054 & 0.113 & $.583 * *$ \\
7 & 1.80 & 1.06 & $.863 * *$ & $.643 * *$ & $.712^{* *}$ & 0.018 & -0.026 \\
8 & 3.94 & 0.52 & & & & \\
\end{tabular}

** Correlation is significant at the 0.01 level (2-tailed).

* Correlation is significant at the 0.05 level (2-tailed).

Pearson's correlation coefficients were used to test linearity assumption. Table 2 shows that there was a significant positive correlation between open communication and organizational citizenship behaviour $\left(\mathrm{r}=.801^{* *}, \mathrm{p}<0.01\right)$. The results also revealed a significant and positive relationship between career development practices and organizational citizenship behaviour $\left(\mathrm{r}=.802^{* *} \mathrm{p}<0.01\right)$, also giving a very strong positive relationship. A correlation of above 0.90 is a strong indication that the variables may be measuring the same thing (Tabachnick \& Fidell, 2013). 
1. Organizational citizenship behaviour

2. Open communication

3. career development

4. Gender

5. Age

6. Education

7. Experience

8. Job position

\subsection{Hypothesis Testing}

These hypotheses $\left(\mathrm{H}_{1}\right.$ and $\left.\mathrm{H}_{2}\right)$ were tested using hierarchical regression. Prior to conducting hierarchical regression analyses, all study variables were standardized as Z-scores to test for interaction terms [46]. Z-standardization of the variables allows easy interpretation of the interaction effects [47].

The first hypothesis of the study stated that there is $n 0 \ldots$. significant effect of open communication on organizational citizenship behaviour. Findings in table 3 showed that open communication had coefficients of estimate which was significant basing on $\beta_{1}=0.33$ ( $p$-value $=0.000$ which is less than $\alpha=0.05$ ) thus failed reject the hypothesis and conclude that open communication has a positive and significant effect on organizational citizenship behaviour. These study findings are supported by [27] who noted that the positive effects of high-quality involved supervisor-subordinate relationships on subordinate behavioural and performance outcomes lead to more commitments by employees. [28] concurred with these findings when he revealed positive association between managements direct communication to employees and the various forms of OCB. Hence, stressing this conceptualization. He noted that if employees feel themselves in high-quality open communication relationship with management, then they are likely to reciprocate the organization by engaging in OCB

$\mathrm{H}_{2}$ specified that career development practices moderate the relationship between open communication and organizational citizenship behaviour $(\beta=.24, \rho<.05)$. So, the null hypothesis was rejected. This was also confirmed by $\mathrm{R}^{2} \Delta$ of .01 which indicate that career development practices moderate the relationship between open communication and organizational citizenship behaviour by $1 \%$. This implies that career development practices enhance the relationship between open communication and organizational citizenship behaviour.

Table 3. Hierarchical regression results for Moderating effect of CDP on the Relationship between open communication and OCB.

\begin{tabular}{|c|c|c|c|c|}
\hline & Model 1 & Model 2 & Model 3 & Model 4 \\
\hline & B (s. e) & B (s. e) & B (s. e) & B (s. e) \\
\hline (Constant) & $0.00(.04)$ & $0.00(.03)$ & $0.00(.03)$ & $0.00(.03)$ \\
\hline Zscore: Gender & $0.02(.04)$ & $0.06(.03)$ & $0.07(.03)^{*}$ & $0.06(.03)^{*}$ \\
\hline Zscore: Age & $0.09(.05)$ & $0.08(.03)^{*}$ & $0.08(.03)^{*}$ & $0.08(.03)^{*}$ \\
\hline Zscore: Education & $0.00(.04)$ & $0.02(.03)$ & $0.01(.03)^{*}$ & $0.00(.03)^{* *}$ \\
\hline Zscore: Experience & $(-0.00(.05)$ & $(-0.02(.04)$ & $(-0.02(.03)$ & $(-0.01(.03)$ \\
\hline Zscore (OC) & & $0.33(.05)^{* *}$ & $0.24(.05)^{* *}$ & $0.12(.07)$ \\
\hline Zscore (CDP) & & & $0.24(.05)^{* *}$ & $0.14(.06)^{*}$ \\
\hline Zscore (OC_CDP) & & & & $0.24(.09)^{*}$ \\
\hline \multicolumn{5}{|l|}{ Model Summary } \\
\hline $\mathrm{R}$ & 0.850 & 0.931 & 0.939 & 0.942 \\
\hline R Square & 0.722 & 0.146 & 0.015 & 0.005 \\
\hline Std. Error of the Estimate & 0.550 & 0.383 & 0.363 & 0.356 \\
\hline \multicolumn{5}{|l|}{ Change Statistics } \\
\hline R Square Change & 0.72 & 0.15 & 0.02 & 0.01 \\
\hline F Change & 97.62 & 50.66 & 22.62 & 7.83 \\
\hline df1 & 5.00 & 4.00 & 1.00 & 1.00 \\
\hline df2 & 188.00 & 184.00 & 183.00 & 182.00 \\
\hline Sig. F Change & 0.00 & 0.00 & 0.00 & 0.01 \\
\hline
\end{tabular}

a Dependent Variable: Zscore (OCB)

$* * \mathrm{p}<.01, * \mathrm{p} .05$

$\mathrm{OC}=$ Open Communication, EI=Employee Involvement, $\mathrm{L}=$ Leadership, WLB=Work life balance and OCB= Organization Citizenship Behavior

Source: Research Data (2020)

Previous scholars reiterated that the most optimal way to know the nature of the interaction effect of the moderator is to plot them in a graph [48]. Mod Graphs help to simplify the interpretation of the complex nature of interactions in the model. Thus, the results in Table 4.25 can be plotted on Mod Graphs to provide a logical interpretation of interaction effects of career development practices on the relationship between open communication and organizational citizenship behaviour. Figure 1 demonstrated that higher levels of career development practices within Kenya Forest Service, North Rift Conservancy showed a steeper slope between open communication and organizational citizenship behaviour, hence, the null hypothesis 5a was not supported. This implied that career development practice positively and significantly 
moderates the relationship between open communication and organizational citizenship behaviour. The findings in figure 1 indicate an enhancing moderation effect where increased levels of CDP result to increased effect of open communication on organizational citizenship behaviour.

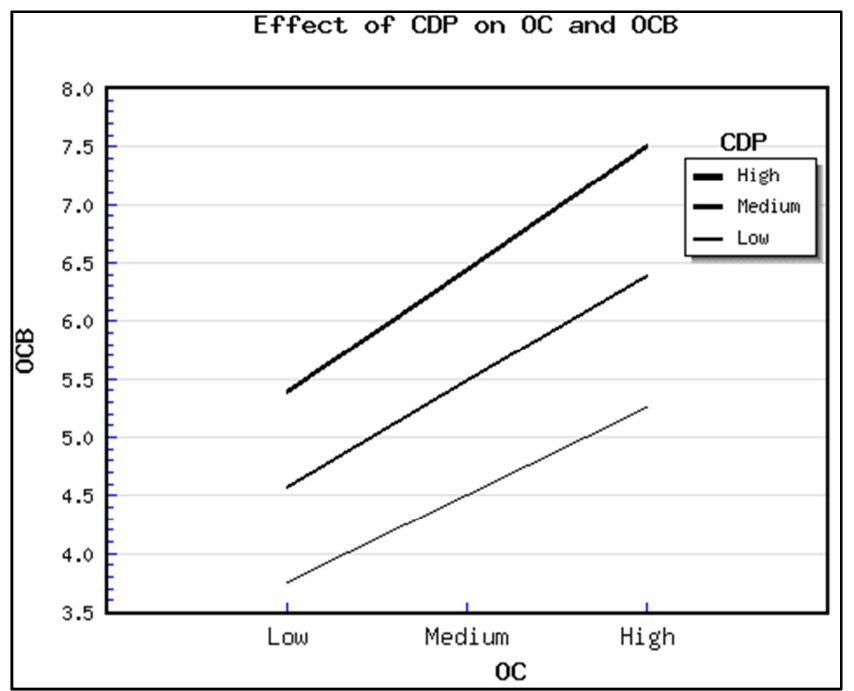

Figure 1. Moderated effect of career development practice on the relationship between open communication and organizational citizenship.

\section{Conclusion}

From the findings, open communication has a positive and significant influence on organizational citizenship behavior. The implication is that open communication is not only necessary to build up proper channels between the management and employees but is also considered as a key dimension to foster employees' organizational citizenship behavior. The relationship between open communication and organizational citizenship behavior is further enhanced when moderated with career development practices. This suggests that efforts by the organization towards ensuring that employees attain career growth leads to an improvement in open communication which in turn fosters organizational citizenship behavior.

The current study provides absolute support to the suggestion that employee retention strategies should be recognized as a significant precursor for the OCB. It can be noted that with career development practices as a moderator retention strategies such as leadership and work life balance become the greatest contributor to OCB. This asserts that the effect of all the employee retention strategies have different strength of relationship with OCB as moderated by career development practices. However, this does not devalue the role of the other retention strategies under study. This implies that the organization should synergistically bundle the employee retention strategies in order to secure maximal OCB besides taking cognizance of career development practices.

\subsection{Theoretical Implication}

The theoretical implication of this study is that it supports and extends the job embeddedness, social cognitive and Social Exchange theory as they have casted more light on social retention strategies and career development practices as a means through which an organization can enhance high OCB. This finding supports the essence of bundling of open communication through mutually consistent policies incarnate of career development strategies and other human resource practices for purposes of galvanizing OCB. The study has addressed the deficiencies in literature by extending studies on open communication, career development and OCB in the Kenyan context as a developing country and specifically in the public sector. Besides, the study has addressed different outcomes of open communication and career development practices which is $\mathrm{OCB}$, other than employee satisfaction and performance as highlighted in a majority of studies.

\subsection{Managerial and Leadership Implication}

The implications of this research findings is that the management of KFS North Rift Conservancy have been enlightened on the need of strengthening the implementation of open communication in consort with career development practices as a means of enhancing OCB. In fine, the findings have contributed to human resource management in terms of providing valuable input to and awareness of the open communication to consider with regard to enhancing OCB. This has been illustrated empirically that the management should strive to synergize their open communication with career development practices in order to achieve maximal OCB.

\subsection{Limitation}

This study faced a number of limitations which have generated implications for future study in the field. The first limitation was that the respondents busy schedules resulting in delayed responses: There was extreme slowness in filling the circulated questionnaires. The explanation from the assigned internal data collection coordinators was that the employees were very busy and therefore, needed more time. In response, the study resorted to researcher-administration of the questionnaire. The researcher administered the questionnaire to the respondents directly at their work stations; where questions were ready to each respondent and responses filled accordingly. The study was limited to the moderating role of career development practices on the relationship between retention strategies and organizational citizenship behavior. Further research may contribute to literature by considering moderating role of career development or other moderators between other retention strategies' and other possible outcomes.

Arising from some of the implications and limitations of the study, recommendations for further research are made. While this study successfully examined the conceptualized framework of open communication, career development practices and OCB. It has also presented a rich prospect for other areas to be researched in future. In terms of industry, the study was only confined to the public sector. It would however be useful to carry out similar study across heterogeneous 
industries. Future research should therefore expand to other industries and contexts because human resource practices and organizational culture vary according to sector and country

\section{References}

[1] Saoula O, Johari H, Fareed M: A conceptualization of the role of organisational learning culture and organisational citizenship behaviour in reducing turnover intention. Journal of Business and Retail Management Research 2018, 12.

[2] Allen RS, Evans WR, White CS: Affective organizational commitment and organizational citizenship behavior: examining the relationship through the lens of equity sensitivity. Organization Management Journal 2011, 8: 218-228.

[3] Emami M, Alizadeh Z, Nazari K, Darvishi S: Antecedents and consequences of organisational citizenship behaviour (OCB). Interdisciplinary Journal of Contemporary Research in Business 2012, 3.

[4] Oakman J, Wells Y: Working longer: What is the relationship between person-environment fit and retirement intentions? Asia Pacific Journal of Human Resources 2016, 54: 207-229.

[5] Tsai Y, Wu SW: The relationships between organisational citizenship behaviour, job satisfaction and turnover intention. Journal of clinical nursing 2010, 19: 3564-3574.

[6] Friedman SD: Succession systems in large corporations: Characteristics and correlates of performance. In Leadership succession. Routledge; 2017: 15-38

[7] Podsakoff NP, Whiting SW, Podsakoff PM, Blume BD: Individual-and organizational-level consequences of organizational citizenship behaviors: A meta-analysis. Journal of applied Psychology 2009, 94: 122.

[8] Baron RM, Kenny DA: The moderator-mediator variable distinction in social psychological research: Conceptual, strategic, and statistical considerations. Journal of personality and social psychology 1986, 51: 1173.

[9] Waheed A: Corporate entrepreneurship and business performance: The moderating role of organizational culture in selected banks in Pakistan. Corporate entrepreneurship and business performance 2016, 2: 18-45.

[10] Kraimer ML, Seibert SE, Wayne SJ, Liden RC, Bravo J: Antecedents and outcomes of organizational support for development: The critical role of career opportunities. Journal of applied psychology 2011, 96: 485.

[11] Okurame D: Impact of career growth prospects and formal mentoring on organisational citizenship behaviour. Leadership \& Organization Development Journal 2012.

[12] Mwai S: KFS Work Environment Survey. Breinscore Consultants Limited.; 2010.

[13] MENR: Ministry of Environment and Natural Resources Strategic Plan 2008 - 2012. Nairobi: Ministry of Environment and Natural Resources.; 2009.

[14] Homans GC: Social behavior as exchange. American journal of sociology 1958, 63: 597-606.

[15] Mulkay M: Functionalism, Exchange and Theoretical Strategy (RLE Social Theory). Routledge; 2014.
[16] Burrell G, Morgan G: Sociological paradigms and organisational analysis: Elements of the sociology of corporate life. Routledge; 2017.

[17] Bankins S: A process perspective on psychological contract change: Making sense of, and repairing, psychological contract breach and violation through employee coping actions. Journal of Organizational Behavior 2015, 36: 1071-1095.

[18] Mowday RT, Porter LW, Steers RM: Employee-organization linkages: The psychology of commitment, absenteeism, and turnover. Academic press; 2013.

[19] Blau P: Exchange and power in social life. Routledge; 2017.

[20] Macey WH, Schneider B, Barbera KM, Young SA: Employee engagement: Tools for analysis, practice, and competitive advantage. John Wiley \& Sons; 2011.

[21] Giri VN, Kumar BP: Assessing the impact of organizational communication on job satisfaction and job performance. Psychological Studies 2010, 55: 137-143.

[22] Shonubi AO, Akintaro AA: The Impact of Effective Communication on Organizational Performance. International Journal of Social Sciences and Humanities Invention 2017, 3: $1904-1914$.

[23] Schein EH: Organizational culture and leadership. John Wiley \& Sons; 2010.

[24] DuFour R, DuFour R: Learning by doing: A handbook for Professional Learning Communities at Work TM. Solution Tree Press; 2013.

[25] Erogluer K: Örgütsel Iletisim ile Is Tatmini Unsurlari Arasindaki Iliskiler: Kuramsal Bir Inceleme/The Relationship Between Organizational Communication and the Aspects of Job Satisfaction: A Theoretical Study. Ege Akademik Bakis 2011, 11: 1409 .

[26] Ince M, Gül H: The role of the organizational communication on employees' perception of justice: A sample of public institution from Turkey. European Journal of Social Sciences 2011, 21: 106-124.

[27] Eisenberger R, Karagonlar G, Stinglhamber F, Neves P, Becker TE, Gonzalez-Morales MG, Steiger-Mueller M: Leadermember exchange and affective organizational commitment: The contribution of supervisor's organizational embodiment. Journal of Applied psychology 2010, 95: 1085.

[28] Kandlousi NSAE, Ali AJ, Abdollahi A: Organizational citizenship behavior in concern of communication satisfaction: The role of the formal and informal communication. International Journal of Business and Management 2010, 5: 51.

[29] Katou AA: Measuring the impact of HRM on organizational performance. Journal of Industrial Engineering and Management (JIEM) 2008, 1: 119-142.

[30] ALDamoe FMA, Yazam M, Ahmid KB: The mediating effect of HRM outcomes (employee retention) on the relationship between HRM practices and organizational performance. International Journal of Human Resource Studies 2012, 2: 75.

[31] Shawabkeh K: Career path development and its impact on organizational citizenship behavior in greater Amman municipality. International Journal of Business and Management 2017, 12: 79. 
[32] Hausknecht JP, Rodda J, Howard MJ: Targeted employee retention: Performance - based and job - related differences in reported reasons for staying. Human Resource Management: Published in Cooperation with the School of Business Administration, The University of Michigan and in alliance with the Society of Human Resources Management 2009, 48: 269-288.

[33] Yang J-T, Wan C-S, Fu Y-J: Qualitative examination of employee turnover and retention strategies in international tourist hotels in Taiwan. International Journal of Hospitality Management 2012, 31: 837-848.

[34] Singh S: Measuring Work-life Balance. International Journal of Advance Research in Computer Science and Management Studies 2014, 17: 15-29.

[35] Gheorghe V: The Moderating Role of Work Locus of Control in Relationship between Interpersonal Communication and Organizational Citizenship Behaviour. Logos, Universality, Mentality, Education, Novelty Section Social Sciences 2018, 7: $1-16$.

[36] Anitha J: Determinants of employee engagement and their impact on employee performance. International journal of productivity and performance management 2014.

[37] Krejcie RV, Morgan DW: Determining sample size for research activities. Educational and psychological measurement 1970, 30: 607-610.

[38] Organ DW: Organizational citizenship behavior: The good soldier syndrome. Lexington Books/DC Heath and Com; 1988.

[39] Yildirim O: The Impact of organizational communication on organizational citizenship behavior: research findings. Procedia-Social and Behavioral Sciences 2014, 150: 1095-1100.

[40] Wane K: Effect Of Career Development Programs On Employee Retention In International Non Governmental
Organizations In Kenya. School Of Business, University Of Nairobi, Kenya 2016.

[41] Burton LJ, Mazerolle SM: Survey instrument validity part I: Principles of survey instrument development and validation in athletic training education research. Athletic Training Education Journal 2011, 6: 27-35.

[42] Beavers AS, Lounsbury JW, Richards JK, Huck SW: Practical considerations for using exploratory factor analysis in educational research. Practical Assessment, Research, and Evaluation 2013, 18: 6.

[43] Yong AG, Pearce S: A beginner's guide to factor analysis: Focusing on exploratory factor analysis. Tutorials in quantitative methods for psychology 2013, 9: 79-94.

[44] Elbashir MZ, Collier PA, Sutton SG, Davern MJ, Leech SA: Enhancing the business value of business intelligence: The role of shared knowledge and assimilation. Journal of Information Systems 2013, 27: 87-105.

[45] Fraenkel JR, Wallen NE, Hyun HH: How to design and evaluate research in education. New York: McGraw-Hill Humanities/Social Sciences/Languages; 2011.

[46] Aiken LS, West SG, Reno RR: Multiple regression: Testing and interpreting interactions. Sage; 1991.

[47] Dawson JF: Moderation in management research: What, why, when, and how. Journal of business and psychology 2014, 29: $1-19$.

[48] Tordera N, Gonzalez-Roma V, Peiró JM: The moderator effect of psychological climate on the relationship between leadermember exchange (LMX) quality and role overload. European Journal of Work and Organizational Psychology 2008, 17: $55-72$ 